\title{
Temperature effect on the maximum swimming speed of jack mackerel Trachurus japonicus through muscle contraction monitoring
}

\author{
Nofrizal (iD) Farhan Ramdhani • Takafumi Arimoto
}

Nofrizal (Corresponding author) - F Ramdhani

Faculty of Fisheries and Marine Science, Riau University, Indonesia, Kampus Bina Widya, Km. 12.5, Simpang Panam, Pekanbaru 28293, Indonesia.

\section{T Arimoto}

Graduate School of Marine Science and Technology, Tokyo University of Marine Science and Technology, Tokyo 1088477, Japan.

email: aan_fish@yahoo.com

\section{Received: March 23, 2020 • Accepted: April 06, 2020 • Published Online: April 21, 2020}

\begin{abstract}
The purpose of this study is to know the effect of temperature on fish muscle contraction of jack mackerel (Trachurus japonicus), which muscle contraction will determine the tail beat frequency and maximum swimming speed. The maximum swimming speed of was evaluated according to the measurement of the muscle contraction time with electric stimuli of 2-7 V, $50 \mathrm{~ms}$. Fish were separated into four groups for temperature acclimation at 10, 15, 18 and 22 ${ }^{\circ} \mathrm{C}$ to reflect typical changes in seasonal water temperature in Japan. Results showed that the swimming speed of the fish was positively related to the tail-beat frequency at all temperatures. The muscle contraction time was also affected by the acclimated temperature, which longer at the lower temperature than higher ones. Mean contraction time (Tm) was $45.1 \mathrm{~ms}$ at $10^{\circ} \mathrm{C}, 32.7 \mathrm{~ms}$ at $15^{\circ} \mathrm{C}, 32.9 \mathrm{~ms}$ at $18^{\circ} \mathrm{C}$, and $31.9 \mathrm{~ms}$ at $22^{\circ} \mathrm{C}$, respectively. The mean of maximum tailbeat frequency (Fmax) obtained from $\mathrm{Fmax}=1 / 2 \mathrm{Tm}$ was 11.4 $\mathrm{Hz}$ at $10^{\circ} \mathrm{C}, 15.8 \mathrm{~Hz}$ at $15^{\circ} \mathrm{C}, 16,4 \mathrm{~Hz}$ at $18^{\circ} \mathrm{C}$, and $16.6 \mathrm{~Hz}$ at $22^{\circ} \mathrm{C}$. These were used to estimate the maximum swimming speed (Umax) at each temperature, resulting in $9.45 \mathrm{FL} \mathrm{s}^{-1}$ at $10{ }^{\circ} \mathrm{C}, 13.5 \mathrm{FL} \mathrm{s}^{-1}$ at $15^{\circ} \mathrm{C}, 14.0 \mathrm{FL} \mathrm{s}^{-1} 18{ }^{\circ} \mathrm{C}$, and 14.2 $\mathrm{FL} \mathrm{s}^{-1}$ at $22{ }^{\circ} \mathrm{C}$. The seasonal temperature effects on the swimming performance of $T$. japonicus, which lower water temperature in the winter made low swimming performance.
\end{abstract}

Keywords: muscle contraction time, swimming performance, tail beat frequency

\section{Introduction}

Swimming activity is an important physiological process for fish survival and plays an important role in swimming behavior, swimming performance (Nofrizal et al 2009), food capture, predator avoidance, and reproductive behavior (Webb 1984). It is required for the development of fishing methods and technology or sustainable fisheries management (Nofrizal and Ahmad 2015; Parrish 1999;
Wardle 1993). Previous studies show that swimming capability and performance of fish are strongly influenced by temperature (Beaamish 1978; Lee et al 2003). Water temperature also has significant effects on swimming endurance, swimming speed, heartbeat activities (Nofrizal et al 2009; Riyanto and Arimoto 2014; Nofrizal and Ahmad 2015), oxygen consumption (Herskin and Steffensen 1998), metabolic rate (Lee et al 2003), muscle contractility (Rome et al 1990; Yanase et al 2007), and swimming performance and impact on the mortality and stress of the trawl fishing operations (Chopin and Arimoto 1995).

Considering the effect of temperature, several related studies have been done to find out the effect toward specific species. Firstly, an investigation conducted by Nofrizal et al (2009) explored how water temperature influences the swimming activities of jack mackerel (Trachurus japonicus). The result pointed out that swimming endurance rises with the increasing temperature (Nofrizal et al 2009: Nofrizal and Arimoto 2011). Secondly, Woohead (1964) found the swimming inability of sea Solea vulgaris to avoid trawl fishing process at lower temperatures in cold waters. At the last, a study to Walleye pollock Theagra chalcogramma showed that the fish is inactive and unable to swim at $2{ }^{\circ} \mathrm{C}$ during a towing process of the trawl (Inoue et al 1993). Those findings bring to a notion that swimming performance of the species including its swimming speed and swimming endurance was influenced by the temperature.

The relationship between swimming speed and endurance can be considered for making decisions on fishing operations and methods, and managing flow velocity in running-water aquaculture systems (Nofrizal and Ahmad 2015). Furthermore, the maximum swimming speed is important information for determining the towing speed of fishing gear such as in trawl and purse seine fishing operation. Thus, the information on how the maximum swimming speed 
is affected by water temperature is required for determining the appropriate fishing methods and operations.

Unlike the previous studies which used ECG as the tool for monitoring swimming performance of the species (Nofrizal et al 2009), this current study investigated the effect of temperature toward swimming speed of jack mackerel through muscle contraction monitoring. Regarding the aforementioned explanations, therefore the hypothesis of this study is that the maximum swimming speed of fish is affected by muscle contraction, which in turn will affect the maximum swimming speed. Hence, this paper focuses on the effect of variable water temperature on the maximum swimming speed, as estimated by the minimum muscle contraction time.

\section{Materials and Methods}

\section{Experimental Fish}

About 300 jack mackerels (18.29 $\pm 0.63 \mathrm{~cm}$ fork length) were obtained from the fish cage in Numazu Bay, Shizuoka Prefecture, Japan $\left(35^{\circ} 06^{\prime} 0.00^{\prime \prime}\right.$ N, $138^{\circ} 52^{\prime} 0.01^{\prime \prime}$ E) and transported to the Fish Behavior Laboratory of Tokyo University of Marine Science and Technology. They were seasonally separated in four groups and acclimated at different water temperatures $\left(10,15,18\right.$ and $\left.22^{\circ} \mathrm{C}\right)$ for over a week. The fish group of $10{ }^{\circ} \mathrm{C}$ was obtained in winter, December to February. The group of 15 and $18{ }^{\circ} \mathrm{C}$ was collected in spring and autumn, March to May and September to November, while that of $22{ }^{\circ} \mathrm{C}$ was collected in summer, June to August. The measurements of muscle contraction were also conducted through water temperature adjustment to season, closely simulating the conditions as experienced by jack mackerels in Japanese waters. The water temperature in the acclimation tank was maintained by thermo controller (REI-SEA, TC-100, Japan) following the seasonal climate temperature during the indoor measurement of the muscle contraction time.

\section{Observation of swimming speed and tail beat frequency}

The tail beat frequency increase following the swimming speed level was observed in the swimming channel of a flume tank (West Japan Fluid Engineering Laboratory, PT-70). The water temperature in the flume tank was maintained at the desired temperature in each fish group (10, 15,18 and $22^{\circ} \mathrm{C}$ ). Each individual was randomly selected and placed in the swimming channel and adapted for 10 minutes to low flow speed $(12.4 \mathrm{~cm} / \mathrm{s})$ conditions. The tail beat frequency was recorded using a video camera (Sony, CCDTRV 96) and video recorder (Sony, EVO 9720) during swimming exercise at various levels of swimming speed, i.e. $20.4,39.3,55.4,74.3,93.1,112.0,128.1,147.0$ and $160.4 \mathrm{~cm}$ $\mathrm{s}^{-1}$, being equal to $1.1,2.1,3.0,4.1,5.1,6.1,7.0,8.0$ and 8.8 $\mathrm{FL} \mathrm{s}^{-1}$, respectively. The tail beat frequency of the individual fish at each swimming speed was counted at the slow-motion mode of the video timer (For-A, VTG-55D) (Figure 1).

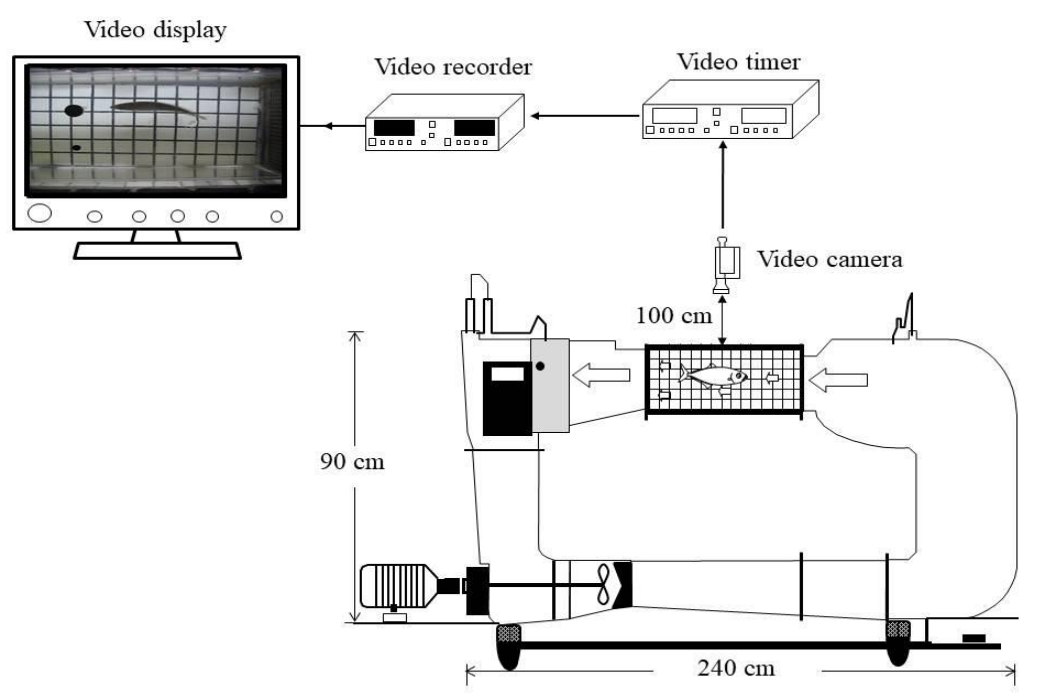

Figure 1 Experimental scheme for tail beat frequency observation at various swimming speed levels.

\section{Measurement of muscle contraction time}

Muscle contraction times were measured using a pair of needles punctured at dorsal muscle of fish body (Figure 2). A needle was connected to the strain gages (KYOWA, Type KFWS-@N-120-Cl-11L3M2R) to detect the muscle contraction when the electric stimuli were given $2-7 \mathrm{~V}, 50 \mathrm{~ms}$.
The muscle of fish body dissected and put on the plate and punctured by a pair needle of the strain gages. The strain gages were connected to the strain-amplifier (DPM-110B). Another needle was connected to the electric stimulator (Nihonkohden, SEN-2201) to give electric stimuli to the fish muscle. Both circuits were connected to the oscilloscope (IWATSU, DS-5102) for monitoring the stimuli interval between the 
given electric stimuli and the muscle contraction on the oscilloscope display. The thermo-controller (TK 200, Takara Industrial Cooperation) maintains the water media in the aquarium during the measurement of muscle contraction time at a designated temperature, or given temperature (Figure 2).

\section{Data analysis}

Minimum muscle contraction time ( $\mathrm{Tm})$ data at given temperatures yield maximum tail frequency $(F \max )$, through an equation as $F \max =1 / 2 \mathrm{Tm}$ (Wardle 1975). The maximum swimming speed (Umax) was estimated by a linear regression between tail beat frequency $(F)$ and maximum swimming speed $\left(U, F L s^{-I}\right)$ at each temperature, $U \max =a+b F$. Oneway ANOVA and ANCOVA by SPSS-IBM version 20 were used to compare the effect of temperature on muscle contraction time, tail beat frequency and to estimate the maximum swimming speed.

\section{Results}

\section{Tail beat frequency monitoring}

Figure 3 shows that swimming speed is positively related to tail beat frequency. The water temperature was a significant effect (ANCOVA, $P>0.05$ ) on the tail beat frequency and swimming. The tail beat frequency increased more than $4 \mathrm{~Hz}$ at the swimming speed more than $3 \mathrm{FL} \mathrm{s}^{-1}$ and reached more than $11 \mathrm{~Hz}$ at the swimming speed more than 9 FL s ${ }^{-1}$ at each water temperature. The tail beat frequency dramatically increased following swimming speed levels. Higher tail beat frequency is making faster swimming speed.

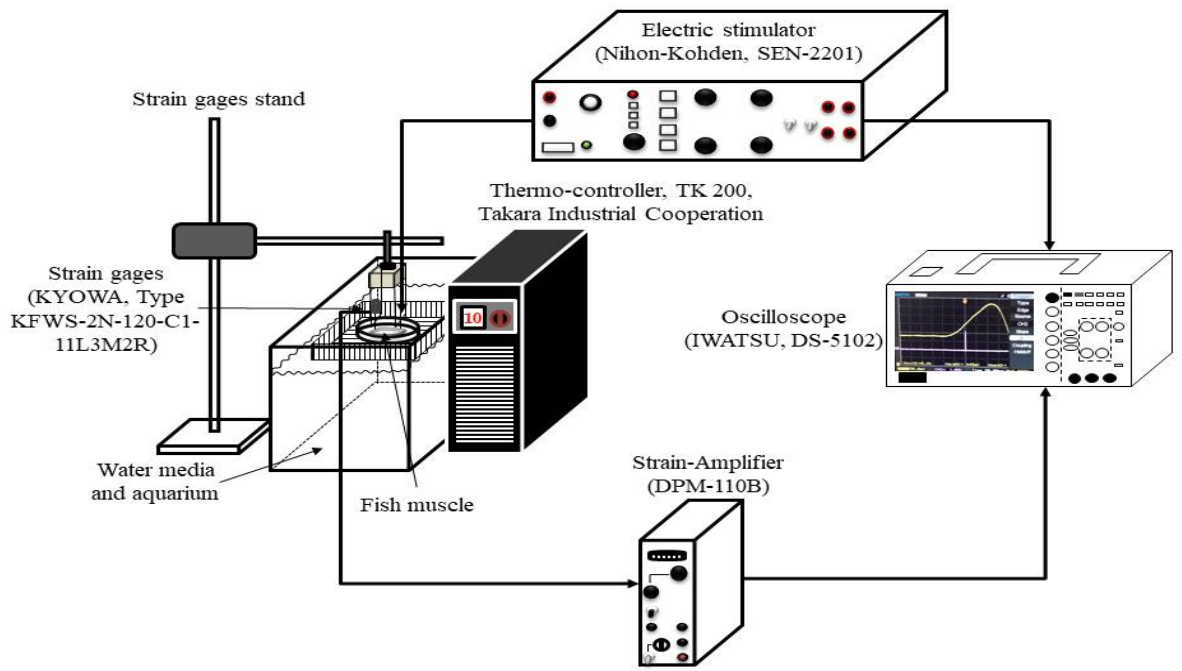

Figure 2 The scheme of muscle contraction time measurement at the water temperature of $10,15,18$ and $22{ }^{\circ} \mathrm{C}$.

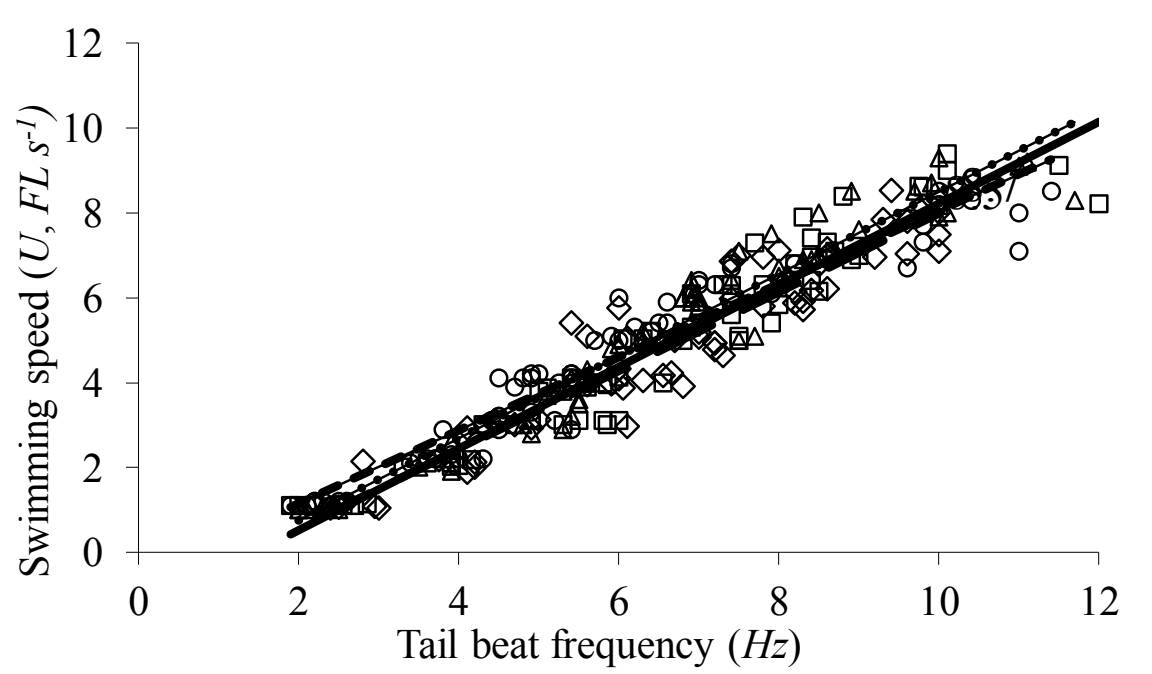

Figure 3 Relationship between tail beat frequency $(F)$ and swimming speed $\left(U, F L s^{-1}\right)$. The circle mark was $10^{\circ} \mathrm{C}(n=68), U, F L s^{-1}=0.86$ $(H z)-0.57, R^{2}=0.92$. Rectangular mark was $15^{\circ} \mathrm{C}(n=68), U, F L s^{-1}=0.86(H z)-1.39, R^{2}=0.93$. Triangle mark was $18^{\circ} \mathrm{C}(n=57), U, F L$ $s^{-1}=0.97(H z)-1.18, R^{2}=0.94$, and diamond mark was $22^{\circ} \mathrm{C}(n=63), U, F L s^{-1}=0.92(H z)-1.28, R^{2}=0.90$. The dot line was linear regression for $10^{\circ} \mathrm{C}$, solid line for $15^{\circ} \mathrm{C}$ and broken line for $22^{\circ} \mathrm{C}$. 


\section{Effect of temperature on muscle contraction}

Minimum muscle contraction time was longer at $10{ }^{\circ} \mathrm{C}$ than at higher temperatures, with values being stable at and above $15^{\circ} \mathrm{C}$ (Figure 4, mean $\pm 1 \mathrm{SD}$, min. - max.: $45.1 \pm 7.3$ $\mathrm{ms}, 36.7-57.5 \mathrm{~ms}$ at $10^{\circ} \mathrm{C} ; 32.7 \pm 6.5 \mathrm{~ms}, 22.7-43.3 \mathrm{~Hz}$ at $15{ }^{\circ} \mathrm{C} ; 32.9 \pm 6.8 \mathrm{~ms} 23.0-38.3 \mathrm{~ms}$ at $18{ }^{\circ} \mathrm{C} ; 31.9 \pm 7.6 \mathrm{~ms}$, $22.7-47.0$ at $\left.22^{\circ} \mathrm{C}\right)$.

\section{Tail beat frequency at various temperatures}

The estimation of tail beat frequency was based on the minimum muscle contraction time of jack mackerel. Faster tail beat frequency is required for faster muscle contraction. Figure 5 shows that the tail beat frequency of jack mackerel was significantly lower (One-way ANOVA, $P<0.05$ ) at a low temperature than that at a higher temperature. The tail beat frequency was $11.4 \pm 1.7 \mathrm{~Hz}$ at $10^{\circ} \mathrm{C}$. The highest tail beat frequency at $10{ }^{\circ} \mathrm{C}$, could reach $13.6 \mathrm{~Hz}$ and the lowest is 8.7 Hz. At $15{ }^{\circ} \mathrm{C}$, the tail beat frequency was $15.8 \pm 3.3 \mathrm{~Hz}$ in average, and as the maximum was $22.1 \mathrm{~Hz}$ and minimum was $11.5 \mathrm{~Hz}$. The average tail beat frequency at $18{ }^{\circ} \mathrm{C}$ was $16.4 \pm$ $3.9 \mathrm{~Hz}$, It could reach $21.7 \mathrm{~Hz}$ as highest and $13.0 \mathrm{~Hz}$ as lowest. The tail beat frequency was $16.6 \pm 3.6 \mathrm{~Hz}$ at $22^{\circ} \mathrm{C}$, and the maximum could reach was $22.1 \mathrm{~Hz}$ and the minimum was $10.6 \mathrm{~Hz}$. However, it did not significantly change $(P>$ $0.05)$ at higher temperature. The range of tail beat frequency for each sample at low water temperature $\left(10^{\circ} \mathrm{C}\right)$ was not diverse compared to the range of tail beat at higher temperatures $\left(18\right.$ and $22{ }^{\circ} \mathrm{C}$ ) (Figure 5).

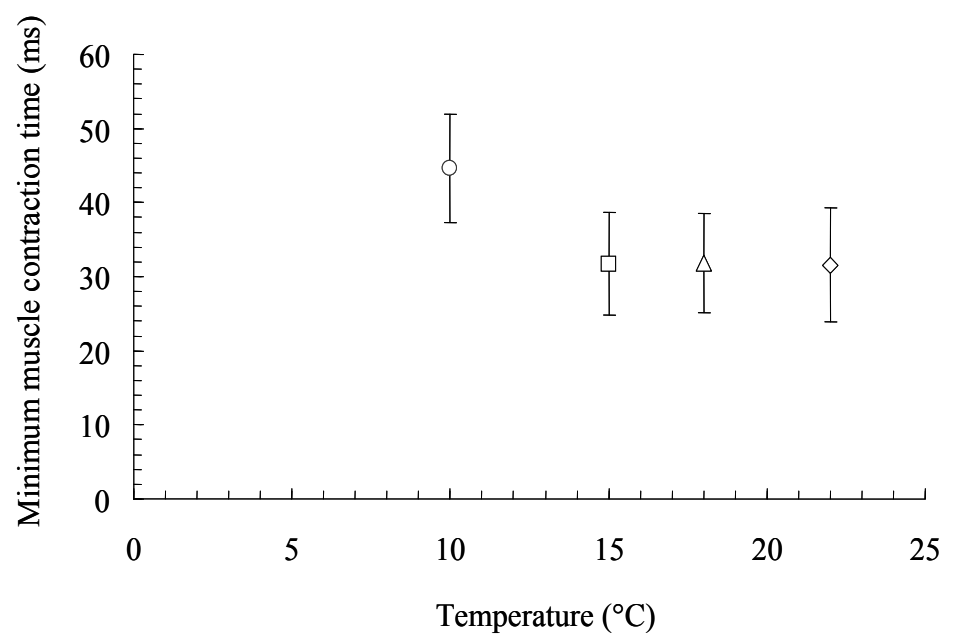

Figure 4 Minimum muscle contraction time $(T m)$ at various water temperatures. The circle mark was $10{ }^{\circ} \mathrm{C}(n=7)$, rectangular mark was 15 ${ }^{\circ} \mathrm{C}(n=9)$, triangle mark was $18^{\circ} \mathrm{C}(n=6)$ and diamond mark was $22{ }^{\circ} \mathrm{C}(n=8)$.

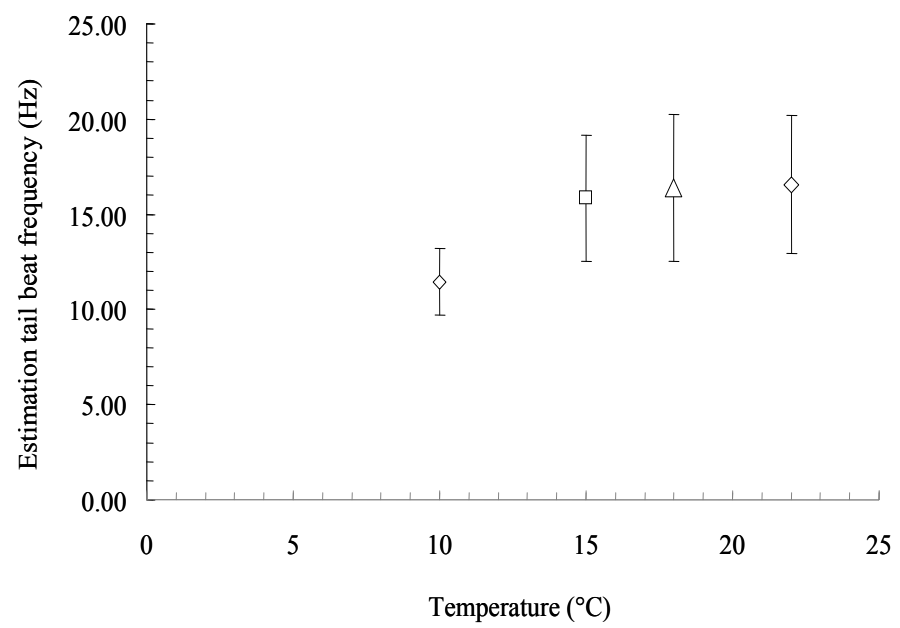

Figure 5 Calculation of tail beat frequency $(F)$ activities by $F=1 / 2 \mathrm{Tm}$ at various water temperatures. The circle mark was $10{ }^{\circ} \mathrm{C}(n=7)$, rectangular mark was $15^{\circ} \mathrm{C}(n=9)$, triangle mark was $18^{\circ} \mathrm{C}(n=6)$ and diamond mark was $22^{\circ} \mathrm{C}(n=8)$. 


\section{Estimation of maximum swimming speed at various} temperatures

According to the tail beat frequency (Figure 5), the maximum swimming speed could be extrapolated from linear regression equation in Figure 3. Maximum swimming speed was higher at higher temperatures $\left(15,18\right.$ and $\left.22^{\circ} \mathrm{C}\right)$ than that at $10^{\circ} \mathrm{C}$. The mean estimated maximum swimming speed was $9.45 \pm 1.64 \mathrm{FL} \mathrm{s}^{-1}$ at $10{ }^{\circ} \mathrm{C}$, it could reach $15.3 \mathrm{FL} \mathrm{s}^{-1}$ as maximum and 10.3 $\mathrm{FL} \mathrm{s}^{-1}$ as minimum. The maximum swimming speed was increased to $13.5 \pm 3.1$ at $15{ }^{\circ} \mathrm{C}$. The maximum swimming speed $23.9 \mathrm{FL} \mathrm{s}^{-1}$ as maximum and 13.2 $\mathrm{FL} \mathrm{s}^{-1}$ as minimum at this temperature. The maximum swimming speed continuously increases as $14.0 \pm 3.6 \mathrm{FL} \mathrm{s}^{-1}$ at $18^{\circ} \mathrm{C}$, it was reached 23.6 as maximum and 14.7 as minimum. At $22^{\circ} \mathrm{C}$, the maximum swimming speed was increased 14.2 $\pm 3.4 \mathrm{FL} \mathrm{s}^{-1}$ at $22{ }^{\circ} \mathrm{C}$, the maximum swimming speed at this temperature could reach $23.9 \mathrm{FL} \mathrm{s}^{-1}$ as maximum and 12.3 as minimum (Figure 6). The deviation of maximum swimming speed of each individual was higher at higher temperatures than that at lowest temperature of $10^{\circ} \mathrm{C}$.

\section{Discussion}

The tail beat frequency of jack mackerel determines its swimming speed. Higher tail beat frequency leads to faster swimming speed. Figure 3 showed that the tail beat frequency at lower temperature $\left(10^{\circ} \mathrm{C}\right)$ was significantly different with other numbers of tail beat frequency at higher temperature (15, $\left.18,22{ }^{\circ} \mathrm{C}\right)$. In fact, at higher temperature, the numbers of tail beat frequency were not significantly different to each other even it is possible that the water viscosity at $15-22{ }^{\circ} \mathrm{C}$ is similar. Thus, similar tail beat frequency is required to produce water motion to impel their body when swimming at each water temperature. Contrastively, various numbers of tail beat frequency are needed for the swimming speed of 2 FL s1 to $9.4 \mathrm{FL} \mathrm{s}-1$. Therefore, it can be said that the water temperature did not influence the tail beat frequency of $T$. japonicus. The result of this study is consistent with previously published work that the water temperature has a relatively small effect on the tail beat frequency (Rome et al. 1992). However, other studies show that temperature affects swimming performance (Beamish 1978; MacNutt et al. 2004; Keen and Farrell 1994; Claireaux et al 2006), swimming cost (Johnston and Temple 2002), maximum swimming speed, muscle shortening, muscle maximum strength (Rome 1990) and swimming endurance of fish (Nofrizal et al 2009). Nonetheless, the different results may come out due to other factors that possibly contribute to the increase of swimming speed were not considered further in this study such as tail amplitude. Although some studies (Hunter 1971) showed that tail amplitude did not change with speed but Palstra and Planas (2013) mentioned in their literature about swimming physiology of the fish that there are some cases showing increases of tail amplitude in higher swimming speed.

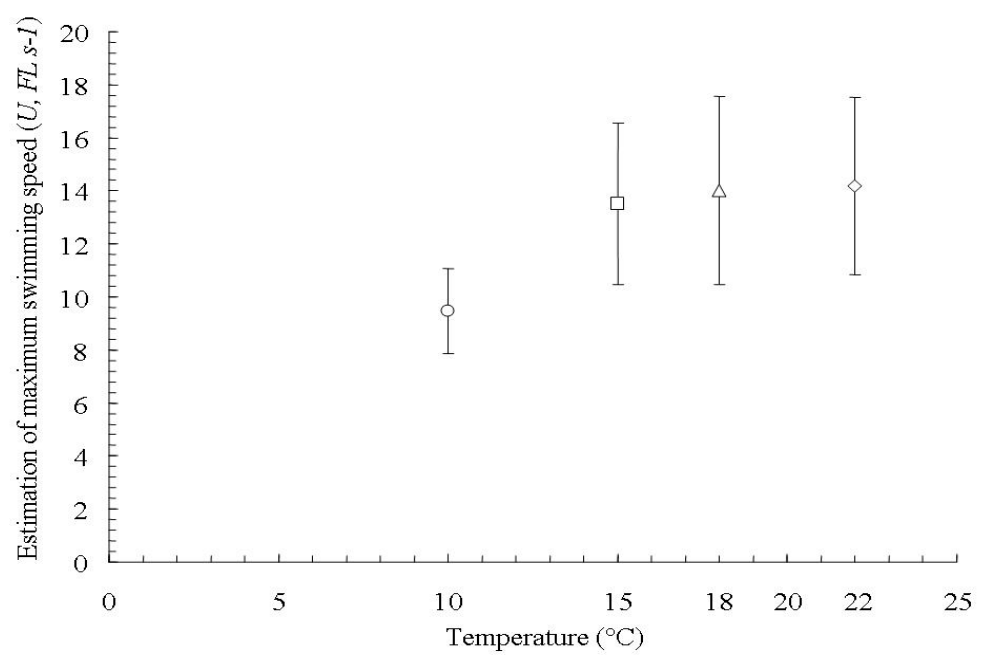

Figure 6 Estimation of maximum swimming speed $\left(U, F L s^{-1}\right)$ at the various water temperatures. The circle mark was $10^{\circ} \mathrm{C}(n=7)$, rectangular mark was $15^{\circ} \mathrm{C}(n=9)$, triangle mark was $18^{\circ} \mathrm{C}(n=6)$ and diamond mark was $22^{\circ} \mathrm{C}(n=8)$.

Furthermore, tail beat frequency is strongly influenced by the speed of the muscle contraction. Based on the observations, the speed of muscle contraction was slower at lower temperatures than at higher temperatures. The ambient water temperature influences the fish's muscle contraction for estimation of the relatively high speed of little tunny (Brill and Dizon 1979; Wardle 1975). The increasing water temperatures have shown the improvement of the muscle contractility (Rome et al 1990; Yanase et al 2007). It could result from that fish muscles experience stiffness at lower temperatures. According to Dickson et al (2002), the swimming activities and the oxidative muscle fiber of chub mackerel (Scomber japonicus) are slow at low temperature. In case at other species show that low water temperature it 
increases the oxidative myotomal muscles of fish, such as in carp (Cyprinus carpio) (Sidel 1980), striped bass (Morone saxatilis) (Jones and Sidel 1982), and rainbow trout (Oncorhynchus mykiss) (Taylor et al 1996). The muscle fiber characteristic of scup (Stenotomus chrysops) changes during the acclimation period at $18{ }^{\circ} \mathrm{C}$ to increase the swimming efficiency (Swank and Rome 2001). Meanwhile, at the present study found that the muscle contraction of jack mackerel is more stable at warmer temperature 15,18 and $22{ }^{\circ} \mathrm{C}$ ). It reflects that $18{ }^{\circ} \mathrm{C}$ is optimum temperature to support the biological activities of jack mackerel, especially the fish swimming activity. This also indicates that optimum muscle contraction of jack mackerel happens at $18{ }^{\circ} \mathrm{C}$.

In this study, the estimation of maximum tail beat frequency is based on the minimum muscle contraction data of each individual at different temperatures. The speed of the tail flicker is lower at lower temperatures than at higher temperatures. Slower muscle contraction results in a lower tail beat frequency. Hence, the maximum swimming speed of jack mackerel was extrapolated from the estimation of tail beat frequency data (see Figure 5) using the linear regression equation (see Figure 3 ). The result shows that the maximum swimming speed of the jack mackerel was slower at lower than at higher temperatures. Fuiman and Batty (1997) reported that the high water temperature could intensify the fish's movement and the fish shows active swimming at the higher temperature. Swimming endurance of jack mackerel increases at higher temperatures at 15,18 and $22^{\circ} \mathrm{C}$ (Riyanto et al 2014; Nofrizal and Arimoto 2011; Yanase et al 2007; Riyanto and Arimoto 2014). For example, Riyanto et al. (2014) found that the swimming speed of jack mackerel improved from 10.9 FL $\mathrm{s}^{-1}$ at $10^{\circ} \mathrm{C}$ to $14.2 \mathrm{FL} \mathrm{s}^{-1}$ at $22{ }^{\circ} \mathrm{C}$. A similar finding by Nofrizal and Arimoto (2011) also confirmed that jack mackerel showed a better swimming performance at higher temperature in which the swimming speed levels of 1.09-9.12 $\mathrm{FL} \mathrm{s}{ }^{-1}$ at 15 and $22^{\circ} \mathrm{C}$.

However, previous studies indicate that in many fish species, the swimming speed and endurance decrease at low temperatures, and increase to the peak at optimal temperatures and then decrease when the temperature approaches the high temperature limit (Randall and Brauner 1991; Myrick and Cech 2000; Ojanguren and Brana 2000; Lee et al 2003).

The present study shows that the deviation of maximum swimming speeds of each individual sample was relatively small at lower temperature (see Figure 6), while at higher temperatures, Trachurus japonicus had more active and faster swimming performance, $16.49 \mathrm{FL} \mathrm{s}^{-1}$ on average or $3.01 \mathrm{~m} \mathrm{~s}^{-1}$ especially at $18{ }^{\circ} \mathrm{C}$. It is indicated by higher standard deviation at each higher water temperature (see Figure 6). The estimation of maximum swimming speed of jack mackerel is faster than that of blue marlin (Makaira nigricans) whose maximum swimming speed rarely exceeds
$2.00 \mathrm{~m} \mathrm{~s}^{-1}$, with a maximum of $2.25 \mathrm{~m} \mathrm{~s}^{-1}$ (Block et al 1992). However, T. japonicus is still considered to be slower than other predator fishes, such as sailfish (Istiophorus platypterus), $8.30 \pm 1.40 \mathrm{~m} \mathrm{~s}^{-1}$, little tunny $5.60 \pm 0.20 \mathrm{~m} \mathrm{~s}^{-1}$, dorado, $4.00 \pm 0.9 \mathrm{~m} \mathrm{~s}^{-1}$ (Svendsen et al 2016), and black marlin (Makaira indica), $30 \mathrm{~m} \mathrm{~s}-1$ (Lane 1941). The standard deviation of swimming speed of jack mackerels was higher at each individual at $18^{\circ} \mathrm{C}$ (Figure 6). This proves that optimum temperatures could make the fish swim more active. Maximum speeds in animals are important in ecological role, especially in relation with the predatory-prey interaction (Wardle 1975; Domenici 2001; Wilson et al 2013). According to Day and Butler (2005), the seasonal water temperatures affect the swimming abilities of fish. This work indicates that water temperature influences the fish maximum swimming speed. The swimming speed decreases when temperature decreases (Hammer 1995; Clsireaux et al 2000; Lee et al 2003b; Fangue et al 2008; Zeng et al 2009; Yan et al 2012; Lee et al 2014). This study concluded that the muscle contraction of $T$. japonicus slowed down in the low temperature. This will cause the fish's tail beat frequency also decline and eventually reduce the fish's maximum swimming speed. In winter, water temperature will certainly fall following the seasonal temperature. This certainly affects fish swimming activity, especially in the fishing process during the winter. In this condition, the fish will be easily caught, because their swimming ability is slower for the fishing gear avoidance during the capture process and predator-prey in trophic level system. Therefore, the fish has great opportunity to escape and avoid the fishing gear during capture process in spring, autumn and summer.

\section{Conclusions}

Ambient water temperature affects the maximum swimming speed of fish. The maximum swimming speed is faster in higher water temperatures $\left(15,18\right.$ and $\left.22^{\circ} \mathrm{C}\right)$ than in lower temperatures $\left(10^{\circ} \mathrm{C}\right)$. In lower waters temperatures, the maximum swimming speed of the fish decreases, this is because fish muscle contractions were stiffer and slower in the lower waters. Slowing fish muscle contraction was indicated by the low average of the muscle contraction time of fish. The low average of muscle contraction time of these fishes affects their tail beat frequency activities. Lower fish muscle contraction times are resulting in a slow the tail beat frequency. Conversely, at a more warming temperature, the fish muscle contraction time is faster; as a result, the tail beat frequency was increased. The tail beat frequency affects the maximum swimming speed. The faster the tail beat frequency is making faster the maximum swimming speed of the fish. Otherwise, the slower tail beat frequency, the lower the maximum swimming speed of the fish. 


\section{Acknowledgments}

We thank the Japan Association Student Service Organization and Academic Recharging Program, Ministry of Research and Technology, Republic of Indonesia for providing and supporting research fund, as well as to all staffs and members of Fish Behavior Laboratory of the Tokyo University of Marine Science and Technology.

\section{Conflict of Interest}

The authors declare no conflict of interest.

\section{References}

Beamish FWH (1978) Swimming capacity. In: Hoar WS, Randal DJ (eds) Fish physiology, Vol 7. London, Academic Press.

Block BA, Booth D, Carey FG (1992) Direct measurement of swimming speed and depth of blue marlin. Journal of Experimental Biologi 116:267-284

Brill RW, Dizon AE (1979) Effect on temperature on isotonic twitch of white muscle and predicted maximum swimming speeds of skipjack tuna, Katsuwonus pelamis. Environmental Biology of Fishes 4:199-205.

Chopin SF, Arimoto T (1995) The condition of fish escaping from fishing gear-a review. Fisheries Research 21:315-327.

Claireaux G, Webber DM, Lagardere JP, Kerr SR (2000) Influence of water temperature and oxygenation on theaerobic metabolic scope of Atlanric cod (Gadus morhua). Journal of Sea Research 44:257265.

Claireaux G, Couturier C, Groison AL (2006) Effect of temperature on maximum swimming speed and cost of transport I juvenile European sea bass (Dicentrarchus labrax). The Journal of Experimental Biology 209:3420-3428.

Day N, Butler PJ (2005) The effects of acclimation to reversed seasonal temperatures on the swimming performance of adult brown trout Salmon trutta. The Journal of Experimental Biology 208:26832692.

Dickson AK, Donley MJ, Sepulveda C, Bhoopat L (2002) Effects of temperature on sustained swimming performance and swimming kinematic of the chub mackerel Scomber japonicas. The Journal of Experimental Biology 205:969-980.

Domenici P (2001) The scaling of locomotors performance in predator-prey encounters: fromfish to killer whales. Comparative Biochemistry and Physiology 131:169-182.

Fangue NA, Mandic M, Richards JG, Schulte PM (2008) Swimming performance and energetics as a function of temperature in killifish Fundulus heteroclitus. Physiological and Biochemical Zoology $81: 389-401$

Hammer C (1995) Fatigue and exercise tests with fish. Comparative Biochemistry and Physiology 112:1-20.

Herskin J, Steffensen JF (1998) Energy saving in sea bass swimming in school: measurements of tail beat frequency and oxygen consumption at different swimming speed. Journal of Fish Biology 53:366-376.

Hunter JR (1971). Swimming speed, tail beat frequency, tail beat amplitude and size in jack mackerel, Trachurus symmetricus, and other fishes. Fisheries Bulletin 69:253-266.
Inoue Y, Matsushita Y, Arimoto T (1993) The reaction behavior of walley pollock (Theragra chalcogramma) in a deep/low-temperature trawl fishing ground. ICES Marine Science Symposium 196:77-79.

Johnston IA, Temple GK (2002) Thermal plasticity of skeletal muscle phenotype in ectothermic vertebrates and its significance for locomotory behaviour. The Journal of Experimetal Biology 205:2305-2322.

Jones PL, Sidell BD (1982) Metabolic response of striped to temperature acclimation. II. Alterations in metabolic carbon sources and distribution of fiber types in locomotory muscle. Journal of Experimental Zoology 219:163-171.

Keen JE, Farrell AP (1994) Maximum prolonged swimming speed and maximum cardiac performance of rainbow trout, Oncorhynchus mykiss, acclimated to two different water temperatures. Comparative Biochemistry and Physiology 108:287-295.

Lane FW (1941) How fast do fish swim? Country Life (London) 90:534-535.

Lee SG, Farrell AP, Lotto A, MacNutt MJ, Hinch SG, Healey MC (2003) The effect of temperature on swimming performance and oxygen consumption in adult sockeye (Oncorhynchus nerka) and coho (O. kisutch) salmon stock. The Journal of Experimental Biology 206:3239-3251.

MacNutt MJ, Hinch SG, Farrel AP, Topp S (2004) The effect of temperature and acclimation period on repeat swimming performance in cutthroat. Journal of Fish Biology 65:342-353.

Myrick CA, Cech JJ (2000) Swimming performance of four California stream fishes: temperature effects. Environmental Biology of Fishes 58:289-295.

Nofrizal, Yanase K, Arimoto T (2009) Effect of temperature on the swimming endurance and post-exercise recovery of jack mackerel Trachurus japonicus, as determined by ECG monitoring. Fisheries Science 75:1369-1375.

Nofrizal (2009) Behavioural physiology on swimming performance of jack mackerel Trachurus japonicus in capture process. $\mathrm{PhD}$ dissertation, Tokyo University of Marine Science and Technology, Tokyo.

Nofrizal, Ahmad, M., 2015. Swimming performance of Asian redtail catfish (Hemibagrus nemurus) in the swimming channel of flume tank. Journal of Sustainability Science and Management 1:107-113.

Nofrizal, Arimoto T (2011) ECG monitoring on swimming endurance and heart rate of jack mackerel Trachurus japonicus during repeated exercise. Journal of Asian Fisheries Society 24:7887.

Ojanguren AF, Brana F (2000) Thermal dependence of swimming endurance in juvenile brown trout. Journal of Fish Biology 56:13421347.

Parrish JK (1999) Using behavior and ecology to exploit schooling fishes. Environmental Biology of Fishes 55:157-181.

Penghan LY, Cao ZD, Fu SJ (2014) Effect of temperature and dissolved oxygen on swimming performance in crucian carp. Aquatic Biology 21:57-65.

Randall DJ, Brauner CJ (1991) Effects of environmental factors on exercise in fish. Journal of Experimental Biology 160:113-126.

Rome LC (1990) Influence of temperature on muscle recruitment and muscle function in vivo. American Journal of Physiology 28:R210R222. 
Rome LC, Sosnicki AA, Choi I (1992) The influence of temperature on muscle function in the fast swimming scup. I. Shortening velocity and muscle recruitment during swimming. Journal of Experimental Biology 163:259-279.

Rome LC, Funke RP, Alexander RM (1990) The influence of temperature on muscle velocityand sustained performance in swimming carp. Journal of Experimental Biology 200:1745-1755.

Riyanto M, Yanase K, Arimoto T (2014). Temperature and fatigue effect on the maximum swimming speed of jack mackerel Trachurus japonicus. Fisheries Science 80: 53-59.

Riyanto M, Arimoto T (2014) The temperature effect on heart rate of jack mackerel Trachurus japonicus during swimming exercise. Fisheries Science 80:1241-1248.

Shadwick RE, Schiller LL, Fudge SD (2013) Physiology of swimming and migration in tunas. In: Palstra AP, Planas JV (Eds) Swimming physiology of fish: Towards using exercise to farm a fit fish in sustainable aquaculture. Springer Science \& Business Media.

Sidell BD (1980) Response of goldfish (Carassius auratus L.) muscle to acclimation temperature: Alterations in biochemistry and proportions of different fiber types. Physiological and Biochemical Zoology 53:98-107.

Svendsen MBS, Domenici P, Marras S, Krause J, Boswell KM, Rodriguez-Pinto I, Wilson ADM, Kurvers RHJM, Viblanc PE, Finger JS, Steffensen JF (2016) Maximum swimming speed of sailfish and three other large marine predatory fish species based on muscle contraction time and stride length: a myth revisited. The Company of Biologist 5:1415-1419.

Swank DM, Rome LC (2001) The influence of thermal acclimation on power production during swimming. II. Mechanics of scup red muscle under in vivo conditions. Journal of Experimental Biology 204:419-430.
Taylor S, Egginton S, Taylor E (1996) Seasonal temperature acclimatisation of rainbow trout: cardiovascular and morphometric influences on maximal sustainable exercise level. Journal of Experimental Biology 199:835-845.

Wardle CS (1993) Fish behavior and fishing gear. In: Pitcher TJ (Ed) The behavior of teleost fishes ( $2^{\text {nd }}$ ed.). Chapman and Hall, London, 609-643 pp.

Wardle CS (1975) Limit of fish swimming speed. Nature 255:725727.

Wilson AM, Lowe JC, Roskilly K, Hudson PE, Golabek KA, McNutt JW (2013) Locomotion dynamics of hunting in wild cheetahs. Nature 498:185-189.

Yan GJ, He XK, Cao ZD, Fu SJ (2012) The trade-off between steady and unsteady swimming performance in six cyprinids at two temperatures. Journal of Thermal Biology 37:424-431.

Yanase K, Eayrs S, Arimoto T (2007) Influence of water temperature and fish length on the maximum swimming speed of sand flathead, Platychephalus bassensis: implication for trawl selectivity. Fisheries research 84:180-188.

Webb PW (1984) Body form, locomotion and foraging in aquatic vertebrates. American Zoologist 24:107-120.

Woodhead PMJ (1964) Changes in the behavior of the sole Solea vulgaris, during cold winters, and the relationship between the winter catch and sea temperature. Helgoland Marine Research 10:328-342.

Zeng W, Cao ZD, Fu SJ, Peng JL, Wang YX (2009) Effect of temperature on swimming performance in juvenile southern catfish (Silurus meridionalis). Comparative Biochemistry and Physiology 153:125-130. 